\title{
Experimental Investigation of the Impact of Necking Position on Pile Capacity Assisted with Transparent Soil Technology
}

\author{
Qingnian Yang, ${ }^{1,2}$ Jianli Shao, ${ }^{1}$ Zhijun Xu $\mathbb{D D}^{3}$ and Yu Miao ${ }^{1}$ \\ ${ }^{1}$ School of Civil Engineering, Nanyang Institute of Technology, Nanyang 473004, China \\ ${ }^{2}$ Henan International Joint Laboratory of Dynamics of Impact and Disaster of Engineering Structures, \\ Nanyang Institute of Technology, Nanyang,473004, China \\ ${ }^{3}$ College of Civil Engineering, Henan University of Technology, Zhengzhou 450001, China \\ Correspondence should be addressed to Zhijun Xu; zj.xu_hust@qq.com
}

Received 11 November 2021; Revised 14 December 2021; Accepted 3 January 2022; Published 7 February 2022

Academic Editor: Qian Chen

Copyright (c) 2022 Qingnian Yang et al. This is an open access article distributed under the Creative Commons Attribution License, which permits unrestricted use, distribution, and reproduction in any medium, provided the original work is properly cited.

\begin{abstract}
Necking in different positions of a pile body has a significant influence on the bearing performance of a single pile. The transparent soil model experiment was adopted to investigate the impacts of necking positions on the vertical bearing capacity of a single pile and the soil deformation around the pile, and subsequently, the causes of the variation of bearing capacity were analyzed. The results show that the existence of necking does not change the bearing behavior of single pile as pile friction resistance. The bearing capacity of piles decreased by $8.21 \%$ and increased by $7.30 \%$ when the necking is located in the shallow and middle pile body, respectively, while it did not change significantly when the defects were in the deep part of the pile. The necking position has a significant effect on the deformation and deformation range of soil. The soils at the top, side, and near the end of a pile were mainly influenced by shallow necking, middle necking, and deep necking, respectively. The soils at the location of necking had apparent settlement phenomenon as the piles subsided. The soils at shallow necking's locations were relatively loose, which reduced the side friction force of piles and finally resulted in a reduction of bearing capacity of a single pile. With the increase of the load, the soil around piles gradually developed penetration phenomenon (large deformation), while the soil at the end of pile moved up against pile settlement, which made the necking soil in the middle denser. The loss of side friction resistance was less than the resistance from the necking, which gave birth to an increase in the bearing capacity of a single pile. It was finally found that the side friction resistance and the resistance caused by necking were the main factors governing the bearing capacity of necking single piles.
\end{abstract}

\section{Introduction}

As an important form of deep foundation, pile foundation has the advantages of high bearing capacity and low settlement rate and is widely used in high-rise buildings, bridges, and ports. Due to the influences of construction technology and other factors, cavity, crack, diameter reduction (necking), and other defects may develop in pile bodies. Such defects were proved to be in presence by integrity inspection of foundation piles $[1,2]$. The existence of these defects will affect the bearing capacity of foundation piles and lead to engineering safety hazards [3-5].

At present, the research on necking piles mainly focuses on the monitoring and identification of the necking.
Svetinskii et al. [6] analyzed the reasons and monitoring methods of necking about the concrete and reinforced concrete piles during the settlement and construction. The position of the defect is determined by Ni et al. [7] by the usage of complex continuous wavelet transform and the analysis of time-frequency phase diagrams of different frequency bands. Schilder et al. [8] proposed a device to detect the integrity of pile body by installing Fabry-Pérot interferometer sensor and fiber Bragg grating sensor at the outside of the pile body. Wang et al. [9] found that necking position had a great influence on the vertical bearing capacity by performing indoor model experiment on the vertical bearing characteristics of normal and necking pile. Zhang [10] found that the formation of necked pile is mainly 
caused by one or more factors, such as improper construction operation, unreasonable mud density design, poor workability of concrete, or unknown soil layer and groundwater in the stratum. However, there is still a lack of systematic research on the bearing capacity of necking pile and the deformation of soil around pile, and therefore it is difficult to reveal the vertical bearing capacity of necking single piles and guide the engineering design.

Transparent soil testing technology overcomes the shortcomings of conventional geotechnical tests in geotechnical engineering [11, 12]. Ezzein and Bathurst [13] proved that transparent soil had typical mechanical properties of granular soil by the results of laboratory shear test, triaxial compression test, and permeability test. For the research of foundation pile, Kong et al. [14] investigated the influence of pile displacement under inclined uplift force on soil mass by using transparent soil test. Xiang et al. [15] studied the influence of rock strength and buried depth on deformation and failure mechanism by conducting transparent soil test and PFC numerical simulations. Yang et al. [16] obtained the refractive index of transparent soil under different porosities and observed the microscopic characteristics of transparent soil by using scanning electron microscope. Liu et al. [17] performed model tests of static-pressure sinking pile by using transparent soil and the particle image velocimetry method. The advantages of full model test over half model test were outlined and the penetration mechanism of static-pressure pile with different pile tip shapes was investigated. Yuan et al. $[18,19]$ developed a measurement system to configure the threedimensional displacement field of soil around piles in transparent soil with the help of particle image velocimetry technology. Liu et al. [20] studied the simulation ability of transparent soil model by comparing the boundary soil displacement field of transparent soil and natural soil model. The test results show that transparent soil can simulate the natural soil. With the development of transparent soil test technology (TSTT), the shortcoming of nonvisualization of geotechnical test has been overcome, and TSTT has become a favorable tool in the geotechnical engineering model testPO. Many scientists have studied and confirmed the preparation method and geotechnical properties of transparent soil. PIV technology is also widely used in geotechnical engineering research, especially in transparent soil test.

To discuss the influence of different neck position on the bearing capacity of single pile, a set of vertical bearing test equipment for single piles using transparent soil was developed. Vertical loading tests were performed using one group of intact piles and three groups of necking single piles at different positions. Load-settlement curves were obtained for the four groups of tests to analyze the influence of necking position on the vertical bearing capacity of single piles. The displacement vector diagram and contour map of four groups of soil around pile corresponding to different loads were calculated by using MatPIV software. The deformation characteristics of soil around piles were studied and the causes for the change of bearing capacity were obtained.

\section{Experimental Work}

2.1. Experimental Setup. The experimental equipment in the present investigation is mainly composed of three parts: loading system, model box, speckle image making system, and image acquisition system. The loading platform can provide a maximum vertical load of $500 \mathrm{~N}$ through a vertical loading rod controlled by a stepper motor. High-strength transparent plexiglass with $5 \mathrm{~mm}$ thickness was adopted to construct the model box. The box had an inner size $320 \times 180 \times 350 \mathrm{~mm}$ (length $\times$ width $\times$ height) [21-23]. The speckle image making system required by the test is placed on the right side of the model box and mainly consists of a $532 \mathrm{~nm}$ laser light source and optical prism. The image acquisition system includes industrial CCD camera and camera control computer. Data collection of the test includes mechanical sensors. One located at the end of the loading rod and its accuracy is $0.3 \mathrm{~N}$. The other one was used to calculate the axial force and the displacement of the loading rod. In the tests, the pressure exertion of the loading system and the control of automatic acquisition scheme were realized by a self-developed computer software. The experimental system is shown in Figure 1.

2.2. Experimental Materials. The fused silica solid particles with particle sizes of $0.5-2 \mathrm{~mm}$ and purity of $99.9 \%$ were selected as solid particles of transparent soil. The size distribution curve is shown in Figure 2. The pore fluid was prepared with $n$-dodecane and 90\# white oil with a volume ratio of $1: 9.5$. Finally, the pore fluid with a refractive index of 1.4590 was obtained at indoor temperature $20^{\circ} \mathrm{C}$. The physical and mechanical parameters are listed in Table 1. All the piles were made of organic glass. Plexiglass is employed as pile material can make the laser side pass through the pile and accurately observe the movement of soil particles, avoid the error caused by the reflecting surface, and the relative strength is low. It can more accurately simulate the actual situation in the small model test. According to the similarity theory [24], a ratio of 1:50 was adopted to reduce the size of the pile studied by Li [25]. The piles had a length and diameter of $200 \mathrm{~mm}$ and $20 \mathrm{~mm}$, respectively. The position and size of necking were designed in the shallow, middle, and deep part of the pile shaft, and the distances from the pile top were 60, 100, and $160 \mathrm{~mm}$, respectively, as shown in Figure 3. During the tests, the model pile experiment was repeated three times and the average magnitudes of three testing results were recorded as the loading data. Since the results of the three tests are basically the same, they will not be displayed. This paper shows the results of the average. In the analysis of soil deformation, the images from the test which had a loading data close to the average value were selected for further analysis.

2.3. Experimental Process. The model pile was placed in the middle of the model box and was embedded to a depth of $200 \mathrm{~mm}$. The laser light was turned on and adjusted to an appropriate position to obtain the soil speckle field required for the experimental, as shown in Figure 4. In this scheme, 


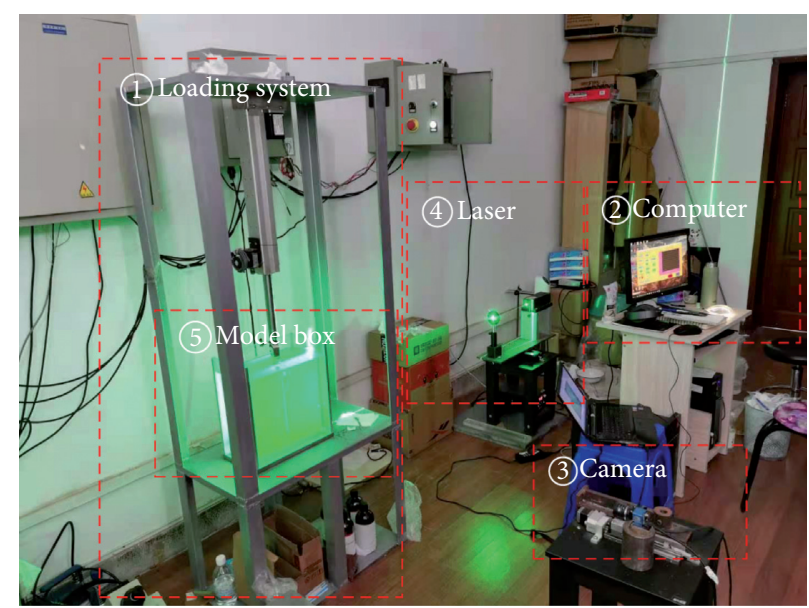

FIgURE 1: Experimental system.

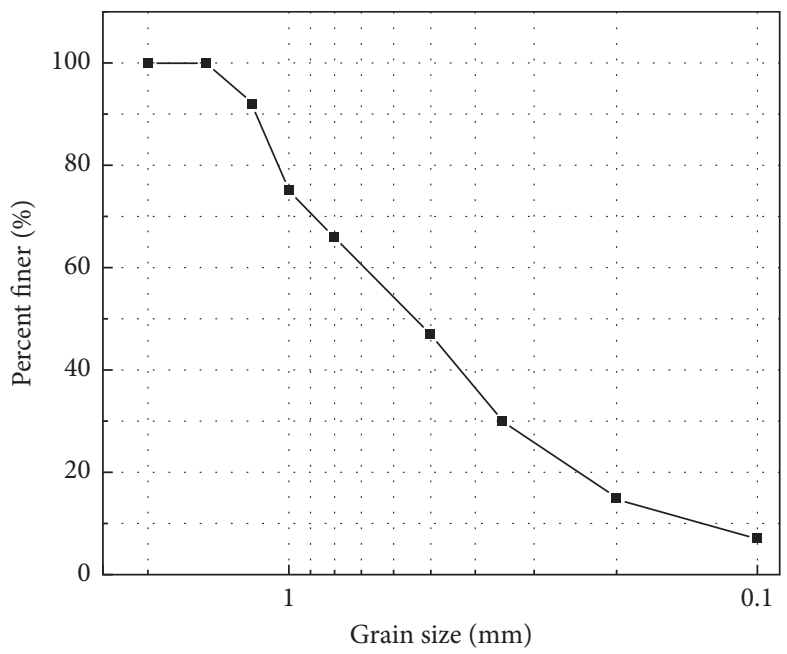

Figure 2: Gradation curve of the fused quartz sand.

TABLE 1: Parameters of transparent soil.

\begin{tabular}{cccccccccc}
\hline$C_{\mathrm{u}}$ & $C_{\mathrm{c}}$ & $\rho_{\mathrm{d}}\left(\mathrm{g} / \mathrm{cm}^{3}\right)$ & $\rho_{\mathrm{d} \max }\left(\mathrm{g} / \mathrm{cm}^{3}\right)$ & $\rho_{\mathrm{dmin}}\left(\mathrm{g} / \mathrm{cm}^{3}\right)$ & $\gamma\left(\mathrm{kN} / \mathrm{m}^{3}\right)$ & $\varphi_{\text {dry }}\left({ }^{o}\right)$ & $\varphi_{\text {soil }}\left({ }^{o}\right)$ & $E_{s}(\mathrm{MPa})$ & $\tau_{\mathrm{f}}(\mathrm{kPa})$ \\
\hline 6 & 1.354 & 1.438 & 1.481 & 1.239 & 2.51 & 37.3 & 38.3 & 11.1 & 10 \\
\hline
\end{tabular}

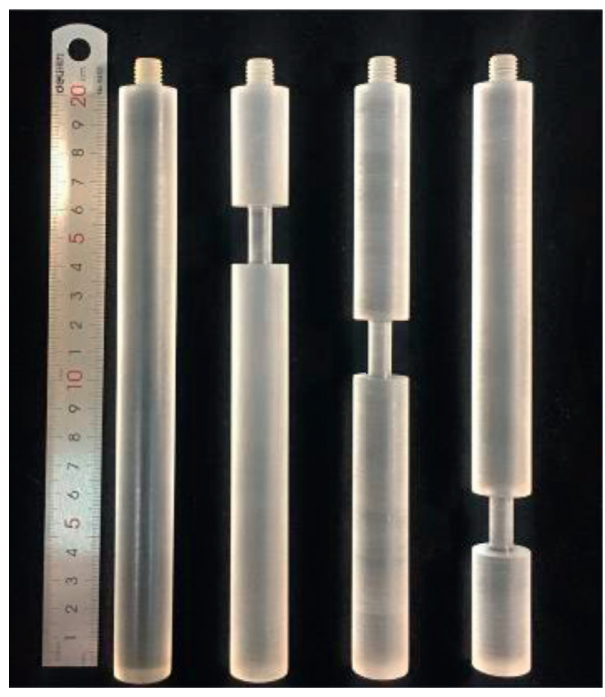

(a)

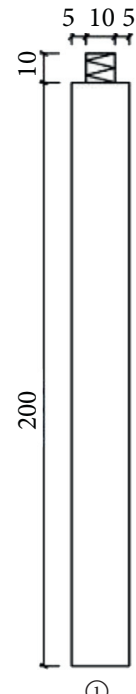

(1)

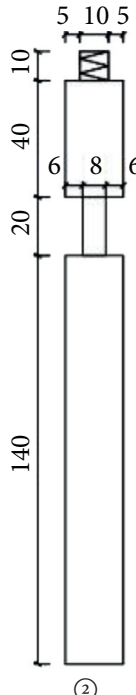

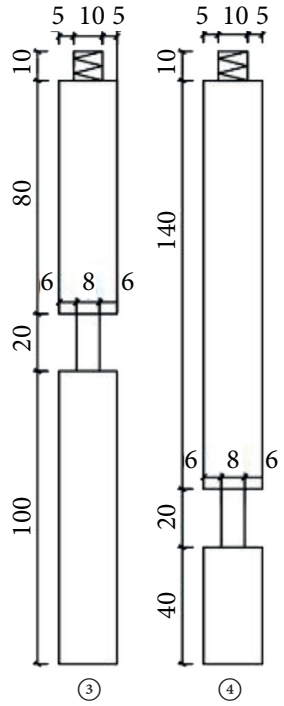

(b)

Figure 3: Physical and dimensions of model piles. (a) Physical model piles. (b) Dimensions of model piles. 


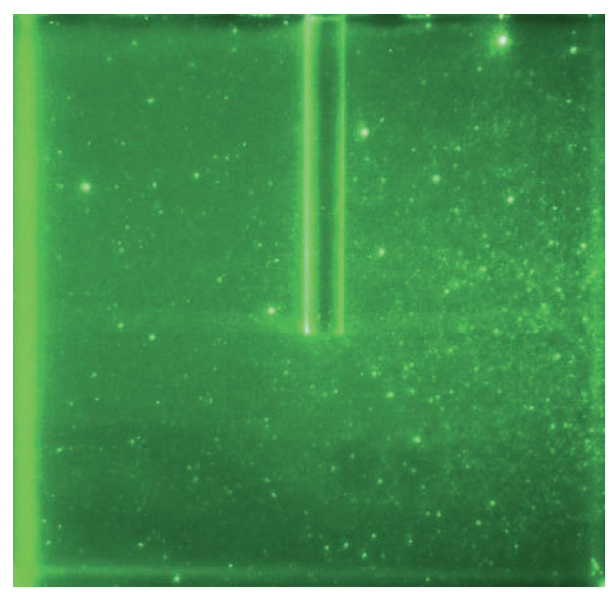

FIGURE 4: Speckle pattern of transparent soil.

the width of the glass box is about $80 \mathrm{~mm}$ away from the pile side, which is 4 times of the pile diameter. The width of the glass box is about $150 \mathrm{~mm}$ away from the pile side, which is 7.5 times of the pile diameter. The height of the glass box is $100 \mathrm{~mm}$ at the pile bottom, which is 5 times of the pile diameter. According to Liu's research results [17], this scheme can eliminate the boundary effect in the test. During the test, transparent soil was laid according to three layers and the thickness of each layer was $100 \mathrm{~mm}$. The model pile was vertically placed into the soil sample when the transparent soils with $50 \mathrm{~mm}$ thickness were laid on the second floor. After that, the subsequent laying was performed. The layout schemes of the model box and pile-soil are shown in Figure 5. To ensure the consistency of the experimental results, the consistency of quality and height of the transparent soil in each model tank should be controlled to ensure the same density of the transparent soil during each experimental preparation. At the same time, to exclude the gas in the granular pores and the internal pore pressure of the soil, the transparent soil after packing was vacuumed.

According to the testing technical code of Building Foundation Piles (JGJ106-2014), the slow-velocity maintenance loading method was adopted to carry out the compressive test of a single pile. The load was applied step by step. The magnitude of loading for each step was $20 \mathrm{~N}$. The loading stability was determined to be stable when the settlement rate of pile top is less than $0.1 \mathrm{~mm} / \mathrm{h}$ for consecutive two times. The settlement of pile top was recorded, and the speckling field of soils was photographed. Then, loading at the next step was applied. When the settlement of pile reached the maximum or the pile body was damaged, the loading ends. The maximum settlement of pile top is limited to $30 \mathrm{~mm}$.

\section{Experimental Results}

3.1. Analysis of Vertical Ultimate Bearing Capacity of Piles. Four groups of load-settlement curves recorded at the pile top were obtained in the tests, as shown in Figure 6. Obvious steep drop can be seen in the curve. According to Testing Technical Code of Building Foundation Pile (JGJ106-2014), the loading magnitude corresponding to the starting point of an apparent steep drop was taken as the ultimate bearing capacity in the steep load-settlement curve. It can be concluded that the vertical ultimate bearing capacity of Nos. 1-4 piles' bodies was 219, 201, 235, and $218 \mathrm{~N}$, respectively. Compared with No. 1 pile (the intact pile), the vertical ultimate bearing capacity (VUBC) of Nos. 2 and 3 piles was reduced by $8.21 \%$ and increased by $7.30 \%$, respectively. For No. 4 pile, the VUBC was almost the same as the intact pile. Before reaching the ultimate loading point, the settlement of the pile top increased almost linearly with the loading applied in the pile top. When the ultimate loading was reached, the settlement in the pile top increased sharply, showing the bearing behavior of friction piles. Therefore, the existence of necking did not change its bearing behavior of friction piles. Before the vertical ultimate load was reached, the settlement magnitudes of necking single piles at the same loading level were all greater than that of No. 1 pile. In total, the necking reduced the side friction, and thus the settlement magnitudes of the necking single piles were greater than those of the intact pile before reaching the vertical ultimate bearing capacity. Although the vertical ultimate bearing capacity of the necking single pile in the middle was improved, the settlement magnitude was still greater than that of the intact pile.

According to the above results, the vertical ultimate bearing capacity of single piles at different necking positions may decrease or increase in comparison with the intact single pile. Therefore, besides side friction, the bearing capacity of single piles should be affected by some other factors. In the following section, the influencing factors will be analyzed in combination with the load-settlement curve of single piles and the soil deformation around the pile.

3.2. Analysis of Soil Deformation under Vertical Loading of Single Piles. The displacement vector map and contour map of soil deformation around piles under different loading levels were obtained by MatPIV software [16, 26]. The loading transfer law of necking single piles and the intact pile under vertical loading was analyzed. The soil deformation field around the pile under 140, 220, and $260 \mathrm{~N}$ loading levels 


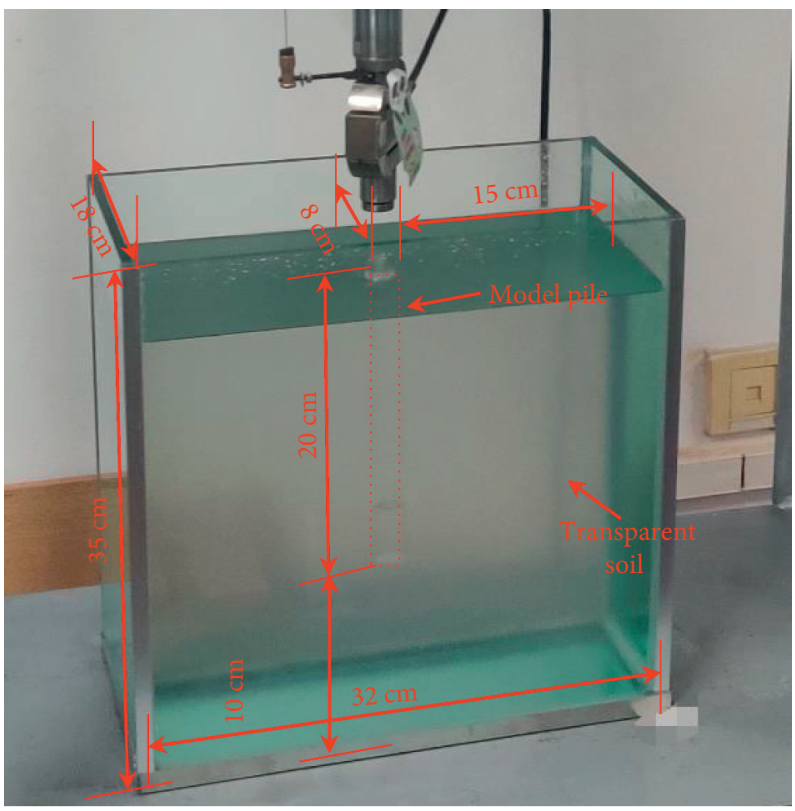

FIgURE 5: Layout of the model box and pile soil.

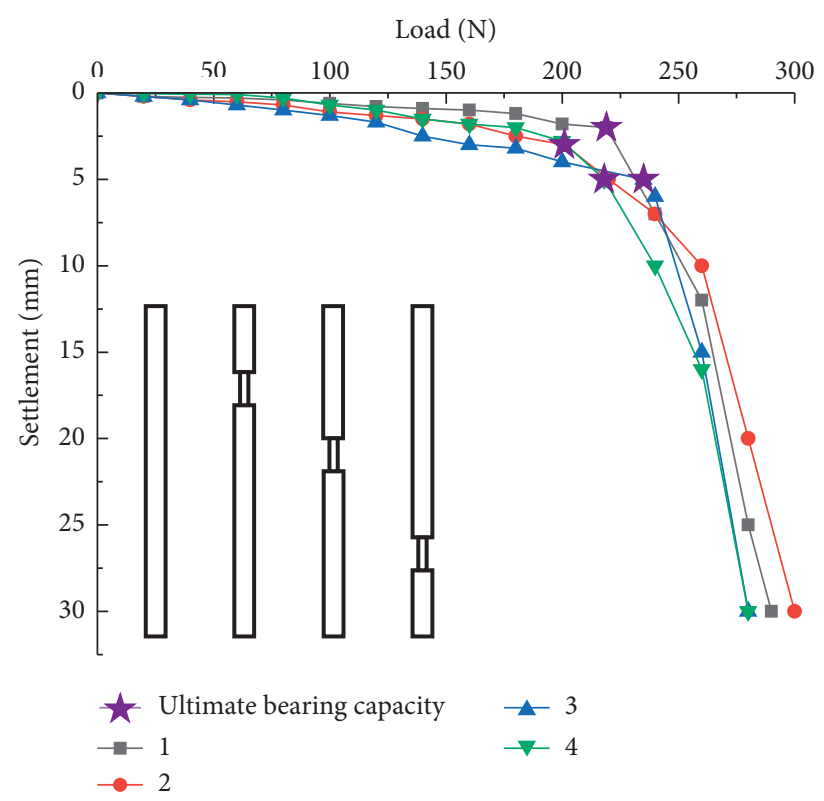

Figure 6: Load-settlement curves.

was selected for analysis. The three load levels stated above were based on the loading of No. 1 pile: $140 \mathrm{~N}$ corresponds to the load before the vertical ultimate bearing capacity of a single pile is reached, $220 \mathrm{~N}$ is the vertical ultimate bearing capacity of a single intact pile, and $260 \mathrm{~N}$ is the load after the vertical ultimate bearing capacity of a single pile. The soil deformation around the three groups of necking piles were compared with each other and also the intact pile. The deformation law of soil around the pile under different loading levels was comprehensively analyzed.
3.2.1. Analysis of Soil Deformation around the Pile under $140 \mathrm{~N}$ Vertical Loading. Each single pile was in the normal bearing range under the $140 \mathrm{~N}$ loading level, and the top settlement magnitudes of Nos. 1-4 single piles were 1, 1.5, 2.5 , and $1.5 \mathrm{~mm}$, respectively. The displacement vector and contour map of the soil around Nos. 1-4 single piles are shown in Figures 7 and 8 under the present loading level 1.

The soils at the pile top and around the pile moved downwards as the sinking of foundation pile under the action of relative friction based on the analysis of Figure 7. 


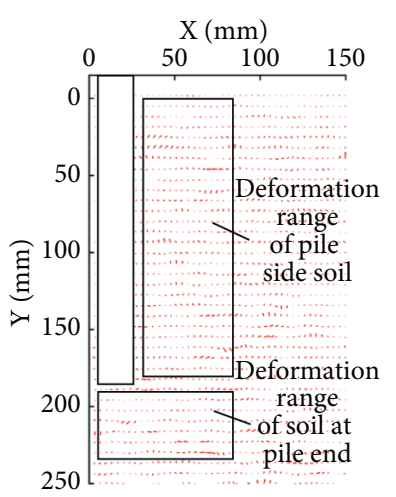

(a)

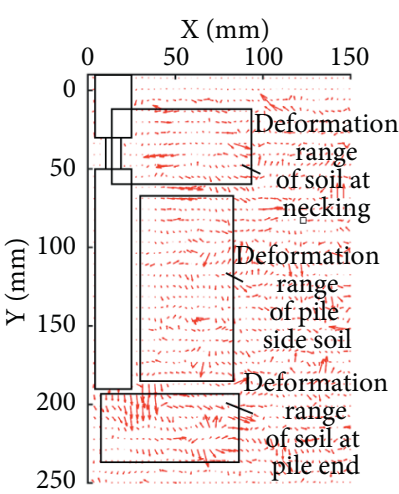

(b)

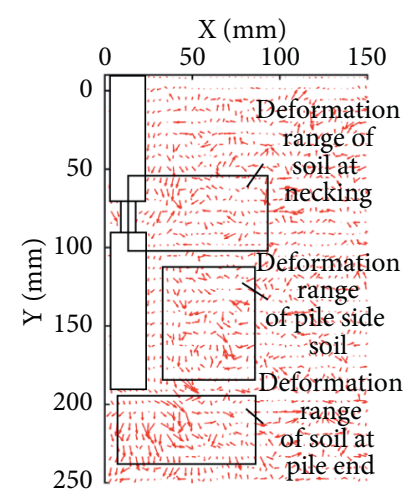

(c)

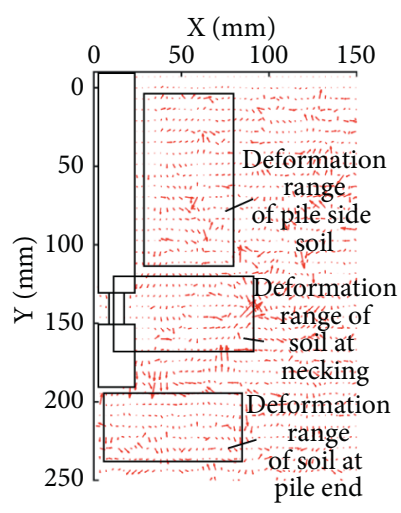

(d)

Figure 7: Displacement vector diagram of soil around the single pile under $140 \mathrm{~N}$ load level. (a) Intact pile. (b) Necking in the shallow pile body. (c) Necking in the middle pile body. (d) Necking in the deep pile body.

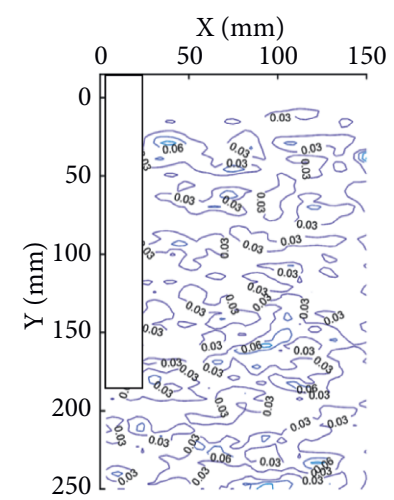

(a)

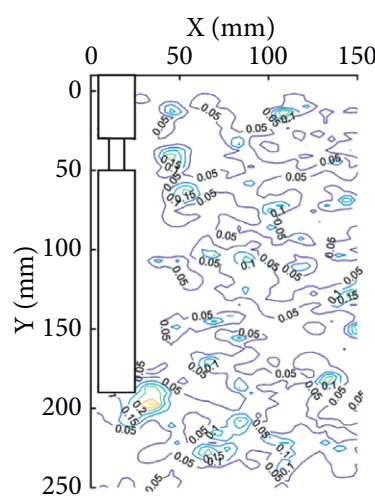

(b)

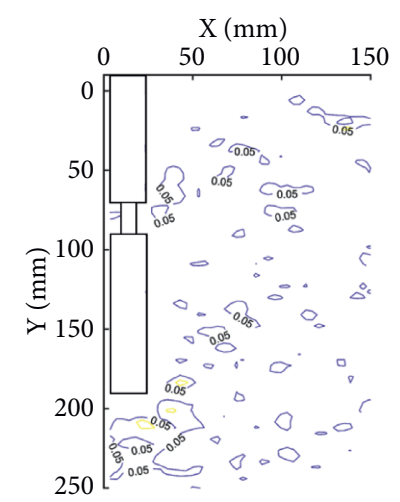

(c)

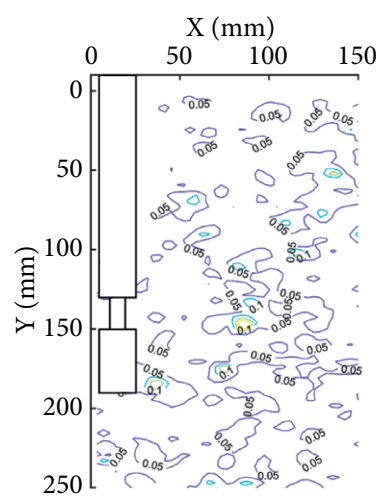

(d)

FIgUre 8: Displacement contour map of soil around the single pile under $140 \mathrm{~N}$ load level. (a) Intact pile. (b) Necking in the shallow pile body. (c) Necking in the middle pile body. (d) Necking in the deep pile body.

The closer the distance between the soil around the pile and the foundation pile, the more obvious the movement of the soil around the pile. By analyzing the test results of Nos. 1-4 pile, the following can be concluded. (1) An increase in the soil deformation around the pile shaft and at the pile top of single necking piles appeared in comparison with the intact pile. Especially, the soil at the necking locations of piles suffered from obvious settlement at the pile shaft. (2) The influence of shallow necking on the soil around the pile is less than that in the middle and deep necking cases.

According to Figure 8, the soil around the pile subsided with the settlement of foundation pile under $140 \mathrm{~N}$ loading. The deformation of the soil around the pile was independent small deformation, while the deformation of the soil at the pile tip was roughly "pear shaped." Compared with No. 1 pile, there was local but relatively limited concentrated deformation at the necking locations of No. 2 pile. Meanwhile, at the pile tip, the deformation was obviously larger than that of the intact pile. For No. 3 pile, there was a large concentrated deformation area in the soils at the necking position, and the deformation of the soil at the pile tip was larger than that of the intact pile, as well as No. 4 pile. But the deformation is smaller than those appeared at the necking locations in the middle. At a close necking position to the pile top, the soil deformation at the pile top had a trend of connecting with the soil deformation at the necking position.

3.2.2. Analysis of Soil Deformation around the Pile under $220 \mathrm{~N}$ Vertical Loading. All single piles had reached their vertical bearing limit except for No. 3 pile at the loading level of $220 \mathrm{~N}$. The settlement magnitudes at the top of Nos. 1-4 piles were $2.8,5,5$, and $5.0 \mathrm{~mm}$, respectively. Displacement vector and contour map of soil around Nos. 1-4 piles under this load level are, respectively, shown in Figures 9 and 10.

According to Figure 9, the pile top settlement of all piles increased with increasing vertical loading. At the same time, the soil around the pile suffered from large deformation. By comparison and analysis of Nos. 1-4 piles, soils at the shallow and middle necking locations moved horizontally away from the foundation pile and moved upwards against the settlement of the pile. At the same time, the soil at the pile top also has a large displacement, and some soils at 


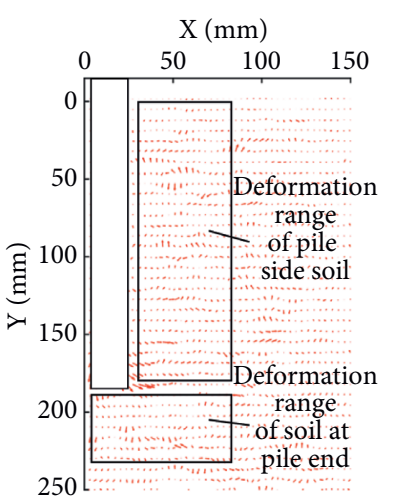

(a)

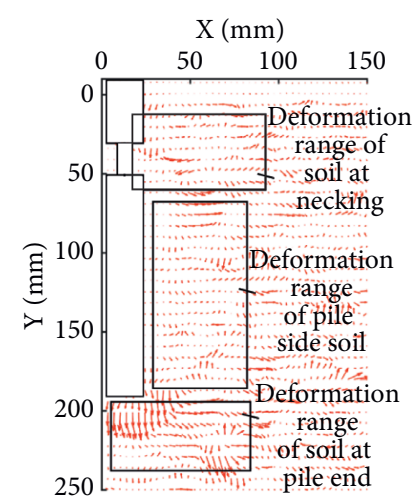

(b)

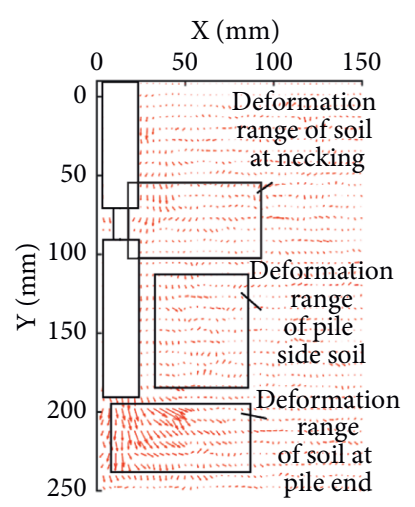

(c)

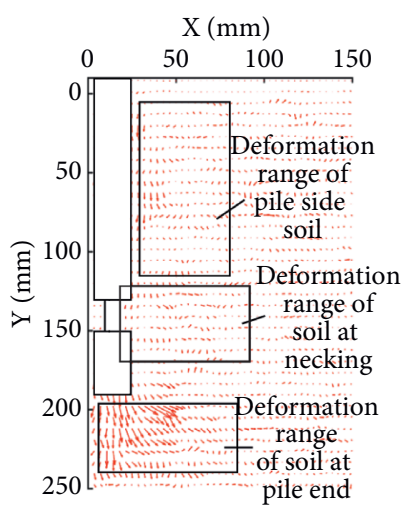

(d)

Figure 9: Displacement vector diagram of soil around the single pile under $220 \mathrm{~N}$ load level. (a) Intact pile. (b) Necking in the shallow pile body. (c) Necking in the middle pile body. (d) Necking in the deep pile body.

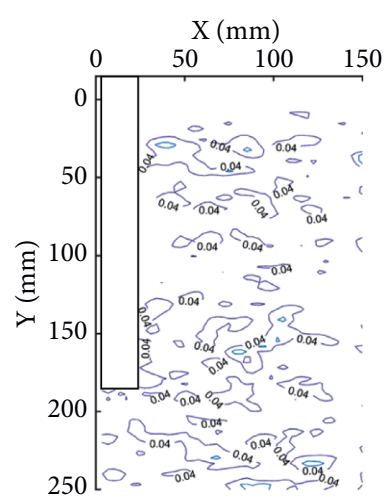

(a)

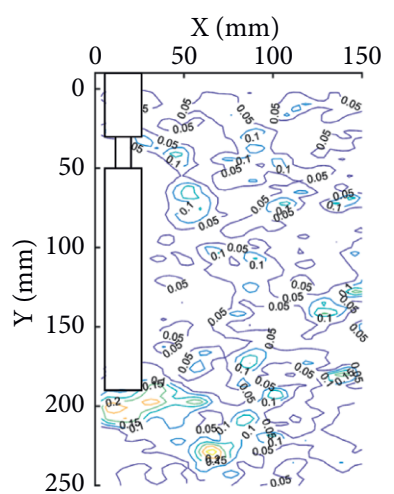

(b)

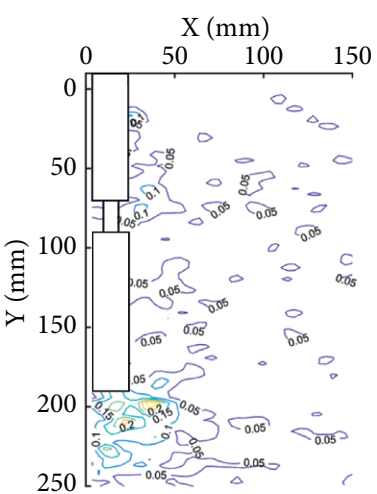

(c)

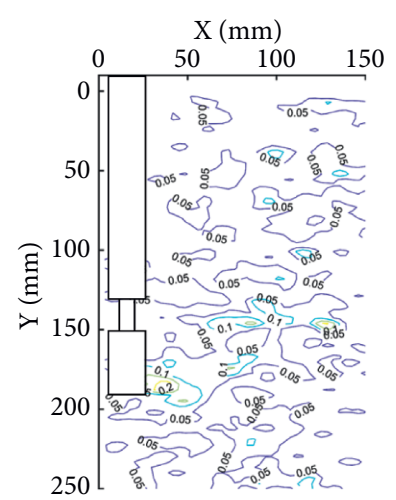

(d)

FIgUre 10: Displacement contour map of soil around the single pile under $220 \mathrm{~N}$ load level. (a) Intact pile. (b) Necking in the shallow pile body. (c) Necking in the middle pile body. (d) Necking in the deep pile body.

the pile top moved upwards around the pile top against the pile settlement. For the deep necking pile, there was a tendency that the deformation of soil around the pile shaft connected with the soil at the pile tip, and a larger part of the soil around the pile from the necking position to the pile top was involved in deformation.

According to Figure 10, with an increase of the load, the deformation magnitude and range of the soil around the pile shaft increased and tended to be gradually through, respectively, while the deformation of the soil at the pile tip gradually changed from the original "pear shape" to the "butterfly shape." Compared with results of No. 1 pile, an increase of the local concentrated deformation in the necking position was observed for No. 2 pile. The soil around the pile forms a circular deformation from the necking position to the pile tip. For No. 3 pile, the concentrated deformation of the soil at the reduced diameter position increased, which resulted in an increase of the affected range of the soil around the pile compared to that of the intact pile. The soil deformation at the necking position of pile No. 4 was connected with the soil deformation at the pile tip, so the soil deformation range near the pile tip increased. For the single pile with a shallow necking (No. 2 pile), when the settlement of the foundation pile was large, the soil at the necking position had obvious concentrated large deformation, and the soil around the pile formed a circular deformation from necking position to the pile tip. For the single pile (No. 3 pile) with middle necking, the affected range of soil at the necking position was larger, which accordingly made the affected range of soil around the pile larger than that of the intact pile. For the single pile with deep necking (No. 4 pile), the deformation range of soil near the pile tip increased as the soil deformation at the necking position was connected with that at the pile tip.

3.2.3. Analysis of Soil Deformation around the Pile under $260 \mathrm{~N}$ Vertical Loading. Each single pile was destroyed under the loading level of $260 \mathrm{~N}$, and the settlement at the pile top increased sharply. The settlement magnitudes of Nos. 1-4 single piles were $18,10,15$, and $16 \mathrm{~mm}$, respectively. Figures 11 and 12 show the displacement vector and contour map of the soil around Nos.1-4 single piles under this loading level. 


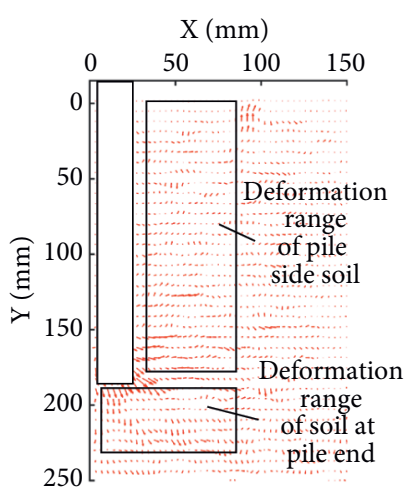

(a)

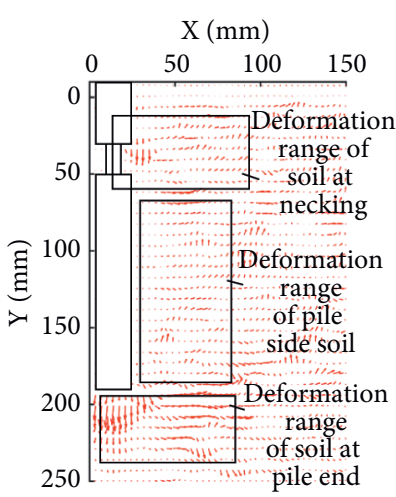

(b)

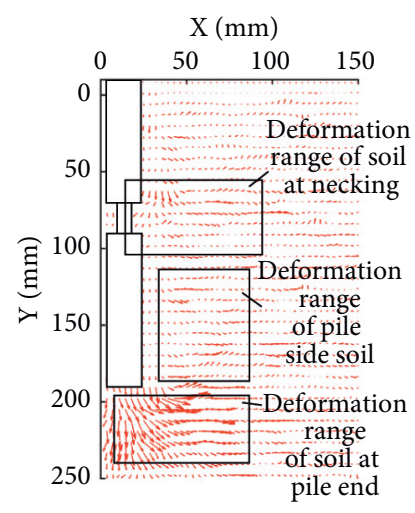

(c)

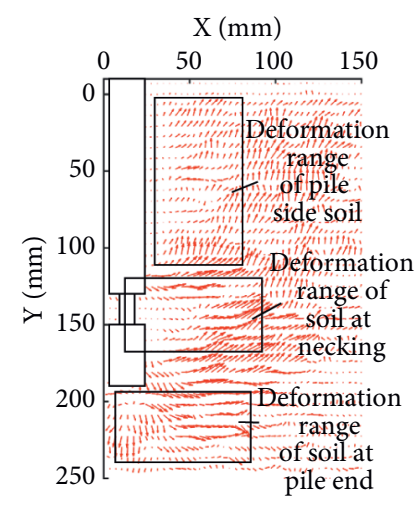

(d)

FIgUre 11: Displacement vector diagram of soil around the single pile under $260 \mathrm{~N}$ load level. (a) Intact pile. (b) Necking in the shallow pile body. (c) Necking in the middle pile body. (d) Necking in the deep pile body.

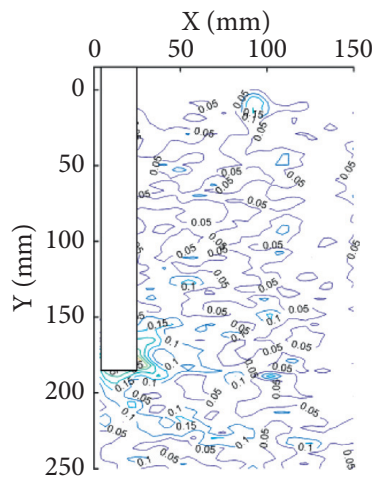

(a)

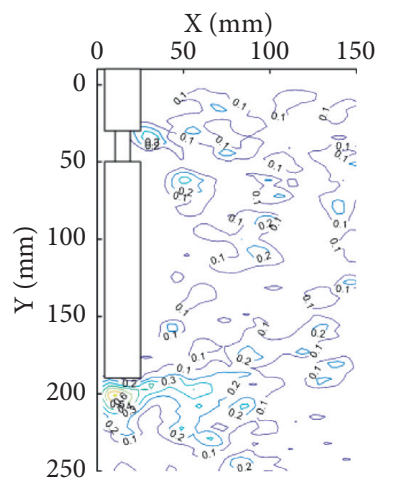

(b)

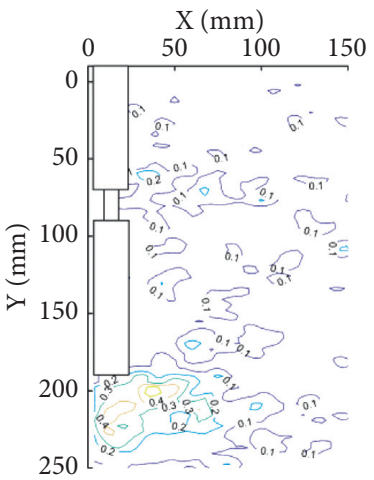

(c)

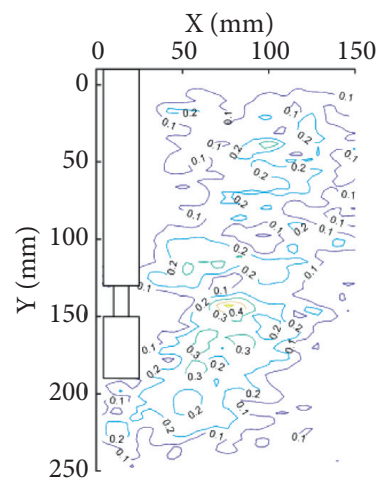

(d)

FIgUre 12: Displacement contour map of soil around the single pile under $260 \mathrm{~N}$ load level. (a) Intact pile. (b) Necking in the shallow pile body. (c) Necking in the middle pile body. (d) Necking in the deep pile body.

It can be found from Figure 11 that the settlement of the single piles increased rapidly when the loading magnitude reached the corresponding vertical bearing capacity of the pile. This subsequently resulted in bulge of soil at the side of piles, settlement of some soil at the tip of piles, horizontal outward movement of some soil around the pile shaft, and upward movement of some soil around the pile end. The bearing capacity of the single piles was lost due to the whole shear damage of soil around the piles. In comparison with the Nos. 1-4 piles and the intact pile, some soil around the necking position settled downward, some soil moved outward in the horizontal direction, and some soil moved upward around the necking tip. Meanwhile, the deformation degree and range increased. For the single pile with deep necking, the soil at the necking location was linked up with the soil at the pile tip and the global deformation range of the soil around the piles increased.

According to Figure 12, combined with the load-settlement curve, each single pile lost bearing capacity with the increase of the load, and the deformation field of the soil around the pile evolved from the original independent deformation to the overall deformation. A failure due to overall deformation occurred and the soil at the pile top completely changed to a "butterfly shape." At this time, the side friction and the pile top resistance of each single pile had reached the maximum. Compared with No. 1 pile, concentrated deformation presented at the necking position of No. 2 pile, the deformation range of the soil between the necking position to the pile tip increased, and the overall deformation range increased. For No. 3 pile, there was concentrated large deformation around the necking position, and the deformation range and magnitude of the soil at the pile top were also large. For No. 4 pile, the deformation of the soil at pile tip decreased slightly. However, the deformation of soil at the pile top was connected with soil at necking position, which resulted in an increase of the deformation range of the soil from the necking location to the pile top.

By analyzing the vertical bearing capacity of single pile and the two-dimensional deformation field of soil under vertical load, it can be concluded that the influence of necking on the vertical bearing capacity of pile comes from pile side friction and necking resistance. For the vertical bearing capacity of single pile, the necking resistance makes 
up for the loss of transverse friction resistance, and the degree of compensation depends on the compaction of soil. The side friction of pile gradually plays a role from top to bottom. For the complete pile, there is no defect in the pile body, so it has greater friction. For a single pile with shallow necking, the upper part of the pile does not provide friction resistance, and the necking resistance cannot make up for the lost side friction, which leads to the reduction of the vertical bearing capacity of the pile compared with the complete pile. For the single pile with middle necking, the soil around the necking position is dense, and the transverse friction resistance at the necking position plays an important role. Therefore, the transverse friction resistance loss is less than the necking resistance, which leads to an increase in the vertical bearing capacity compared with the complete pile. For a single pile with deep necking, the transverse friction loss is equal to the necking resistance, so the bearing capacity of a single pile with deep necking is the same as that of a complete pile. For the soil around the pile, the necking resistance leads to the concentrated deformation of the soil at the necking. With the increase of load, the range of concentrated deformation increases. With the increase of necking depth, the deformation of soil at the necking and the deformation of soil at the pile end increase. This leads to increased deformation of the soil around the pile.

\section{Conclusions}

The influence of the necking position on the vertical bearing capacity of single piles was investigated by using the transparent soil test and PIV image processing technology in the present paper. The influence of necking position on the deformation of soil around the pile under vertical load was intuitively analyzed, and the mechanism of the bearing capacity variation was revealed. The following conclusions were derived:

(1) The load-settlement curves of each single pile showed an obvious steep-drop characteristic. According to the soil deformation diagram, the soil around the pile moves downward with the settlement of the pile foundation before the failure. The single pile loses its bearing capacity due to the shear failure of soil around the pile. Therefore, for friction pile, necking will not change the bearing behavior of single pile as friction pile, nor will it change the failure mode of single pile.

(2) The effect of necking on the vertical loading bearing capacity of a pile comes from side friction and necking resistance. While the two resistances are determined by the compactness of the soil at the necking position of the pile. Compared with the intact pile, the vertical bearing capacity of the middle and shallow necking single pile increases by $7.30 \%$ and decreases by $8.21 \%$, respectively. While for the deep necking single pile, the capacity remains unchanged. The settlement magnitude of the necking single piles is greater than that of the intact pile before the ultimate bearing capacity.
(3) Concentrated deformation at the necking position was observed for the soil around the pile shaft and a large soil deformation range was identified. The main deformation range of the soil around the pile is controlled by the necking position. The shallow necking affects the deformation of the soil near the pile tip, the middle necking affects the deformation of the soil around the pile, and the deep necking affects the deformation of the soil near the pile end.

(4) Combined with transparent soil and PIV technology, this paper studies the variation law of the bearing capacity of reduced diameter pile and the soil around the pile, which provides a certain theoretical and technical reference for the rational design and reinforcement of foundation pile. However, the study is only for a single sandy soil, and other soil conditions have not been studied. The study only considers the variation law and causes of bearing capacity under vertical load, not horizontal load. The theoretical calculation of the influence of shrinkage on bearing capacity has not been deeply studied, and the next research will be carried out in the future.

\section{Data Availability}

The data used to support the findings of this study are available from the corresponding author upon request.

\section{Conflicts of Interest}

The authors declare that there are no conflicts of interest regarding the publication of this paper.

\section{Acknowledgments}

The authors express their gratitude to the National Natural Science Foundation of China (no. 51978247) and Key Science and Technology Projects of Henan Province (no. 202102310242).

\section{References}

[1] Z. Li and Y. Gao, "Effects of inner soil on the vertical dynamic response of a pipe pile embedded in inhomogeneous soil," Journal of Sound and Vibration, vol. 439, no. 2, pp. 129-143, 2019.

[2] M. O'neill and H. Sarhan, "Structural resistance factors for drilled shafts considering construction flaws," in Proceedings of the Current Practice Future, pp. 166-185, Trend Deep Foundation, California, USA, July 2004.

[3] H. A. Sarhan, M. W. O’Neill, and K. M. Hassan, "Flexural performance of drilled shafts with minor flaws in stiff clay," Journal of Geotechnical and Geoenvironmental Engineering, vol. 128, no. 12, pp. 974-985, 2002.

[4] H. Sarhan, M. O'neill, and S. Tabsh, "Structural capacity reduction for drilled shafts with minor flaws," ACI Structural Journal, vol. 101, no. 3, pp. 291-297, 2004.

[5] M. O'neill, S. Tabsh, and H. Sarhan, "Response of drilled shafts with minor flaws to axial and lateral loads," Engineering Structural, vol. 25, no. 1, pp. 47-56, 2003. 
[6] E. V. Svetinskii and M. S. Gaidai, "Defects of precast and castin-place piles in foundation engineering," Soil Mechanics and Foundation Engineering, vol. 32, no. 2, pp. 63-65, 1995.

[7] S.-H. Ni, Y.-Z. Yang, P.-H. Tsai, and W.-H. Chou, "Evaluation of pile defects using complex continuous wavelet transform analysis," NDT \& E International, vol. 87, no. 4, pp. 50-59, 2017.

[8] C. Schilder, H. Kohlhoff, D. Hofmann, F. Basedau, and M. Herten, "Static and dynamic pile testing of reinforced concrete piles with structure integrated fibre optic strain sensors," in Proceedings of the Fifth European Workshop Optical Fibre Sensors, pp. 47-62, Krakow, Poland, May 2013.

[9] C. Wang, J. Su, and G. Wang, "Model test studies of the vertical bearing behavior of bored piles with breakage defects," Applied Mechanics and Materials, vol. 256-259, pp. $65-70,2013$.

[10] M. Zhang, "Experimental researches and numerical analyses of vertical bearing behavior of boredpile foundations including defective piles with stem enlargement or shrinkage," Master Dissertation, Tianjing University, Tianjing, China, 2012.

[11] M. Iskander, "Introduction to transparent soils," in Modelling with Transparent Soils Visualizing Soil Structure Interaction and Multiphase Flow, non-intrusively, pp. 1-4, Springer, Berlin, Heidelberg, 2010.

[12] M. Iskander, R. Baturst, and M. Omidvar, "Past, present, and future of transparent soils," Geotechnical Testing Journal, vol. 38, no. 5, pp. 393-401, 2015.

[13] F. Ezzein and R. Bathurst, "Transparent sand for geotechnical laboratory modeling," Geotechnical Testing Journal, vol. 34, no. 6, pp. 590-601, 2011.

[14] G. Kong, Z. Cao, H. Zhou, and X. Sun, "Analysis of piles under oblique pullout load using transparent-soil models," Geotechnical Testing Journal, vol. 38, no. 5, pp. 725-738, 2015.

[15] Y. Xiang, H. Liu, W. Zhang, J. Chu, D. Zhou, and Y. Xiao, "Application of transparent soil model test and DEM simulation in study of tunnel failure mechanism," Tunnelling and Underground Space Technology, vol. 74, no. 4, pp. 178-184, 2018.

[16] X. Yang, G. Jin, M. Huang, and K. Tang, "Material preparation and mechanical properties of transparent soil and soft rock for model tests," Arabian Journal of Geosciences, vol. 13, pp. 343-352, 2020.

[17] C. Liu, X. Tang, H. Wei, P. Wang, and H. Zhao, "Model tests of jacked-pile penetration into sand using transparent soil and incremental particle image velocimetry," KSCE Journal of Civil Engineering, vol. 24, no. 4, pp. 1128-1145, 2020.

[18] B. Yuan, M. Sun, Y. Wang, L. Zhai, Q. Luo, and X. Zhang, "Full 3D displacement measuring system for 3D displacement field of soil around a laterally loaded pile in transparent soil," International Journal of Geomechanics, vol. 19, no. 5, Article ID 04019028, 2019.

[19] B. Yuan, M. Sun, L. Xiong, Q. luo, and H. Li, "Investigation of 3D deformation of transparent soil around a laterally loaded pile based on a hydraulic gradient model test," Journal of Building Engineering, vol. 28, no. 3, Article ID 101024, 2019.

[20] J. Liu and M. G. Iskander, "Modelling capacity of transparent soil," Canadian Geotechnical Journal, vol. 47, no. 4, pp. 451-460, 2010.

[21] J. P. Xu, J. Zhou, C. Y. Xu, and C. Y. Zou, "Model test research on pile driving effect of squeezing against soil," Rock and Soil Mechanics, vol. 21, no. 3, pp. 235-238, 2000.

[22] Z. H. Cao, G. Q. Kong, H. L Liu, and H. Zhou, "Model test on deformation characteristic of pile driving in sand using PIV technique," Engineering Mechanics, vol. 31, no. no8, pp. 168-174, 2014.

[23] K. R. Massarsch and C. Wersaell, Cumulative Lateral Soil Displacement Due to Pile Driving in Soft Clay, Geo-Congress, San Diego, California, US, 2013.

[24] S. Iai, "Similitude for shaking table tests on soil-structure-fluid model in 1g gravitational field," Soils and Foundations, vol. 29, no. 1, pp. 105-118, 1989.

[25] Z. Y. Li, "Key problems investigation on non-destructive integrity detection of piles with elevated-cap(beam)," Doctoral Dissertation, Zhejiang University, Hangzhou, China, 2017.

[26] Y. Sang, Z. Wang, S. Yu, and H. Zhao, "The loading test on the singe pile with pile cap in transparent soil model," Geotechnical Testing Journal, vol. 42, no. 2, pp. 385-406, 2019. 